\title{
Topical Bevacizumab Therapy in Graft Rejection After Penetrating Keratoplasty
}

\author{
Sandeep Saxena and Neha Sinha \\ Department of Ophthalmology, C.S.M. Medical University \\ (Erstwhile King George's Medical University) Lucknow, \\ India
}

\section{Introduction}

Neovascularization is defined as formation of new vessels from vascular endothelial cells derived from existing blood vessels. These new immature vessels are friable. They have increased permeability, lack structural integrity, and can result in lipid deposition and corneal opacities. Ultrastructurally, corneal neovascularization is characterized by vessels encroaching through separated stromal lamellae. Corneal vascularization following penetrating keratoplasty may result in graft rejection.

\section{Pathophysiology}

Angiogenesis is a complex processs. First, inflammatory mediators trigger vasodilation and increase vascular permeability of limbal and conjunctival vasculature. Vascular endothelial growth factor (VEGF) is one of the most important regulators of corneal angiogenesis. It is produced primarily by macrophages, T cells, and smooth muscle cells in ocular surface.

A second important regulator of corneal neovascularization is basic fibroblast growth factor (bFGF) and the third important signal is platelet aggregation factor (PAF). Others include insulin like growth factor, integrins, transforming growth factor, tumor necrosis factor and matrix metalloproteinase.

Corneal neovascularization can be prevented by various anti angiogenic factors that have been identified in the cornea. Angiostatin, a proteolytic fragment of plasminogen prevents neovascularization and also induces regression of existing vessels. This has been identified in chronic contact lens user where it suppresses the angiogenic stimuli of hypoxia. Second antiangiogenic factor is endostatin which is a proteolytic fragment of collagen XVIII inhibits bFGF and VEGF stimulated corneal neovascularization. Third naturally occurring antiangiogenic factor is pigment epithelium derived growth factor (PEDF) which is a serine protease inhibitor and inhibits bFGF stimulated corneal neovascularization.

Corneal neovascularization most frequently results from corneal oxygen deprivation, or hypoxia. In response to this hypoxia, the body attempts to provide necessary nutrients and oxygen to the deprived corneal tissues by the creation of new blood vessels. During the early stages, this abnormal growth of blood vessels may produce no signs at all, or it may 
cause a variety of symptoms, including eye pain and excessive tearing, light sensitivity, redness, intolerance to contact lenses, and decreased vision.

\section{Role of Corneal Neovascularization in Corneal Graft Rejection}

Corneal neovascularization remains a significant risk factor for corneal graft rejection and subsequent graft failure after penetrating keratoplasty. The collaborative corneal transplantation study ${ }^{1}$ identified, in addition to several other factors, the extent of stromal vessels (quadrants) as a serious risk factor for corneal graft failure. During corneal neovascularization, an upregulation of angiogenic factors is seen in association with down regulation of antiangiogenic molecules. Studies in human and rat models have found vascular endothelial growth factor (VEGF) to be up regulated in inflamed and vascularized cornea.$^{2}$ In a mouse model, it was observed that corneal avascularity during development is redundantly regulated. Lack of the antiangiogenic factors thrombospondin (TSP)-1 and/or 2 resulted in no spontaneous corneal angiogenesis. By contrast, TSP-1, more than TSP-2, helped to suppress inflammation-induced corneal angiogenesis postnatally, implying that angiogenic privilege in the cornea is actively maintained.$^{3}$ Bachmann et $\mathrm{al}^{4}$ in a mouse model found that neutralization of VEGF-A after high-risk corneal transplantation effectively inhibited postoperative hemangiogenesis, lymphangiogenesis, and recruitment of antigen-presenting cells, thereby improving corneal graft survival.

Vascular endothelial growth factor promotes several steps of angiogenesis, including proteolytic activities, endothelial cell proliferation, migration, and capillary tube formation . 5 Topical or systemic application of bevacizumab inhibited both inflammation-induced angiogenesis and lymphangiogenesis in the cornea. This finding suggestes an important role of VEGF-A in corneal lymphangiogenesis and bevacizumab may be useful in preventing immune rejections after penetrating keratoplasty.

\section{Types of corneal vascularization}

Superficial: In superificial corneal vascularization, vessels arrange in arborizing pattern in subepithelial layer and can be traced with conjunctival vessels. This type of vascularization may be observed in trachoma, and phlyctenular conjunctivitis.

Deep: In deep corneal vascularization, vessels are derived from anterior ciliary artery and lie in corneal stroma. Vessels are usually straight and not anastomosing. This type of vascularization may be observed in graft rejection, interstitial keratitis, deep corneal ulcer, and chemical burn.

Pannus: In pannus, extensive superficial vascularization occurs with cellular infiltration. It is of two types:

- Progressive: Infiltration is ahead of vascularization

- Regressive: Infiltration is behind the vascular leash.

\section{Associated symptoms}

Symptoms of corneal neovascularization often include the following:

- $\quad$ Eye pain

- Redness

- $\quad$ Tearing and photophobia 
- Contact lens intolerance

- Decreased vision

\subsection{Advantages of neovascularization}

- Transport humoral and cellular elements of immunological defence and raw material

- Repair and regeneration

- Carry antibiotic and drugs to site of infection

- Eliminates toxic substances

\subsection{Disadvantages of neovascularization}

- Interfere with corneal transparency

- Graft rejection and failure in keratoplasty

- Sensitization to other antigen

\subsection{Complications}

- Corneal edema

- Corneal opacity

- Graft rejection in keratoplasty

- $\quad$ Lipid keratopathy

- Intrastromal/subepithelial bleeding

- It can also lead to blindness

\section{Management}

Corneal neovascularization is one of the main risk factor for immune rejection after corneal transplantation. Healthy cornea is devoid of blood vessels and is said to be immune privileged. When corneal grafts are placed into an avascular recipient corneal bed (low risk keratoplasty) the two year survival rate approaches $90 \%$ under cover of steroids.

The survival rates of corneal grafts placed over vascularized recipient beds (high risk keratoplasty) decrease significantly. Even in low risk setting, mild angiogenesis develops after keratoplasty and increase risk of immune graft rejection. For this reason aggressive treatment of neovascularization may be necessary prior to corneal transplant surgery to ensure lower risk of graft rejection.

Various antiangiogenic agents may be used in management of post keratoplasty graft rejection:

- Angiostatic steroids

- Vascular endothelial growth factor inhibitor

- Protein kinase c inhibitor

- $\quad$ MMP inhibitor

- COX-2 inhibitor

- Antioxidants

- $\quad$ Dietary derived inhibitor

Corticosteroids and systemic immunosuppression remain an important aspect in prevention of post keratoplasty graft rejection. Corticosteroids inhibit macrophages that release growth 


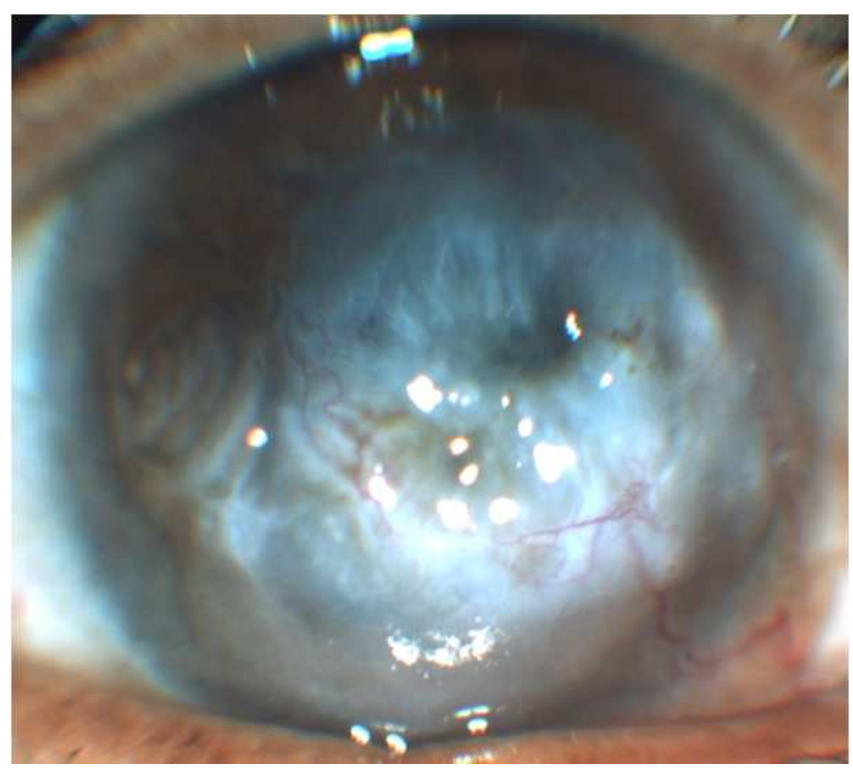

A

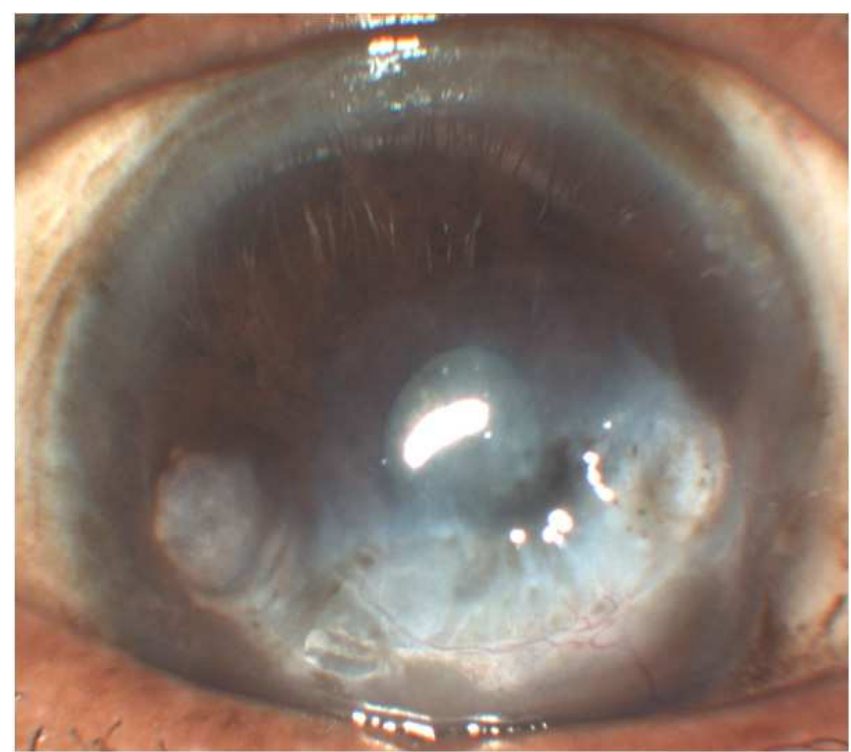

B

Fig. 1. Effect of topical bevacizumab in a case of corneal neovascularization. A. Pretreatment: Corneal vascularization and stromal haze is visible. B. Post-treatment: Marked regression in corneal vascularization and stromal haze has resulted. 
factor. They also prevent intercellular adhesion leading to leukocyte adhesion and migration. They can slow the progression of neovascularization, but cannot stabilize or reverse the process.

Vascular endothelial growth factor inhibitors are emerging as the new pharmacological therapy in the management of post keratoplasty graft rejection. Anti-VEGF agent has been found to be effective in reducing corneal vascularization (Fig. 1). Currently available antiVEGF agents include:

- Bevacizumab (Avastin) Bevacizumab is a humanized monoclonal antibody that inhibits all active isoforms of VEGF and is approved by USFDA since February 2004 for treatment of metastatic colorectal cancer.

- Ranibizumab (Lucentis) Ranibizumab is also a humanized monoclonal antibody fragment highly related to bevacizumab structurally.

- Pegaptanib (Macugen) Pegaptanib is a synthetic oligonucleotide that binds the pathologic isoform of VEGF, which is VEGF 165 and this binding, happens extracellular.

\subsection{Role of bevacizumab in the treatment of corneal vascularization}

Efficacy of bevacizumab therapy has been highlighted in several studies. Manzano et al ${ }^{6}$ in an experimental study on rats showed that a concentration of $4 \mathrm{mg} / \mathrm{mL}$ bevacizumab limits corneal neovascularization. Dastjerdi et al 7 in their study used 1\% bevacizumab for 3 weeks in 10 eyes of 10 patients and followed them up to 24 weeks. They found that short-term topical bevacizumab therapy reduced the severity of corneal neovascularization without local or systemic adverse effects. Chen et $\mathrm{al}^{8}$ used subconjunctival injection of bevacizumab in doses $0.25-2.5 \mathrm{mg}$ twice per week for 2 to 8 weeks in rabbits and concluded that it is effective in preventing corneal neovascularization in acute phase of various kinds of corneal inflammation. Carrasco ${ }^{9}$ reported the use of bevacizumab in an 81-year old woman with corneal neovascularization secondary to herpetic stromal keratitis. Treatment with subconjunctival bevacizumab showed regression of corneal neovascularization. Bock et al ${ }^{10}$ in their study used topical bevacizumab $(5 \mathrm{x} /$ day; $5 \mathrm{mg} / \mathrm{ml})$ for 15 days in corneal neovascularization of various cause and concluded that it inhibits corneal neovascularization without obvious corneal epithelial side effects.

\subsection{Role of bevacizumab in the treatment of corneal vascularization after keratoplasty}

Efficacy of bevacizumab therapy has been highlighted in several studies. Schollmayer et al11 performed a retrospective case series study of nine eyes of nine patients with corneal transplant and neovascularization. Five eyes were administered topical bevacizumab $5 \mathrm{mg} / \mathrm{ml} 4$ times daily for a month. Three eyes were administered bevacizumab subconjunctivally $2.5 \mathrm{mg} / 0.1 \mathrm{ml}$ and one eye was administered bevacizumab both topically as well via subconjunctival route. After a follow up of 6 months, it was concluded that topical and subconjunctival bevacizumab is effective in regressing neovascularization in keratoplasty patients.

Saxena et al ${ }^{12}$ used topical bevacizumab $(4 \mathrm{mg} / 4 \mathrm{ml})$ in dose of one drop twice daily for 15 days in a patient of corneal graft rejection and did a follow up after 1 month, 6 month and 9 months. After 1 month, his BCVA improved to 20/120 from finger counting 1 meter. Corneal vascularization and stromal haze regressed. After 6 months, his BCVA improved to 20/60 


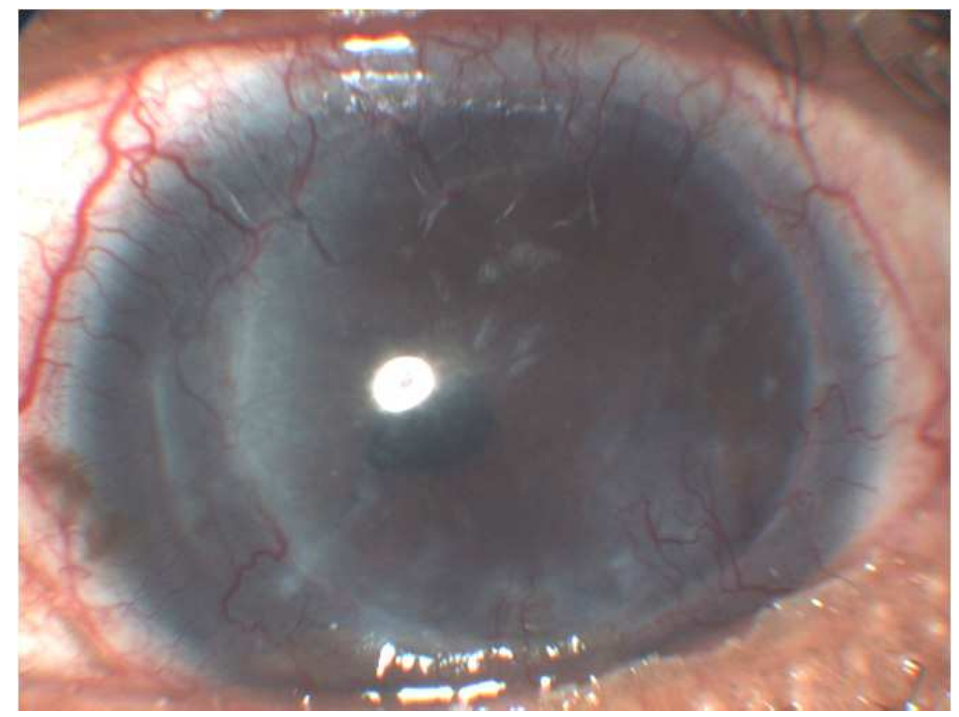

A

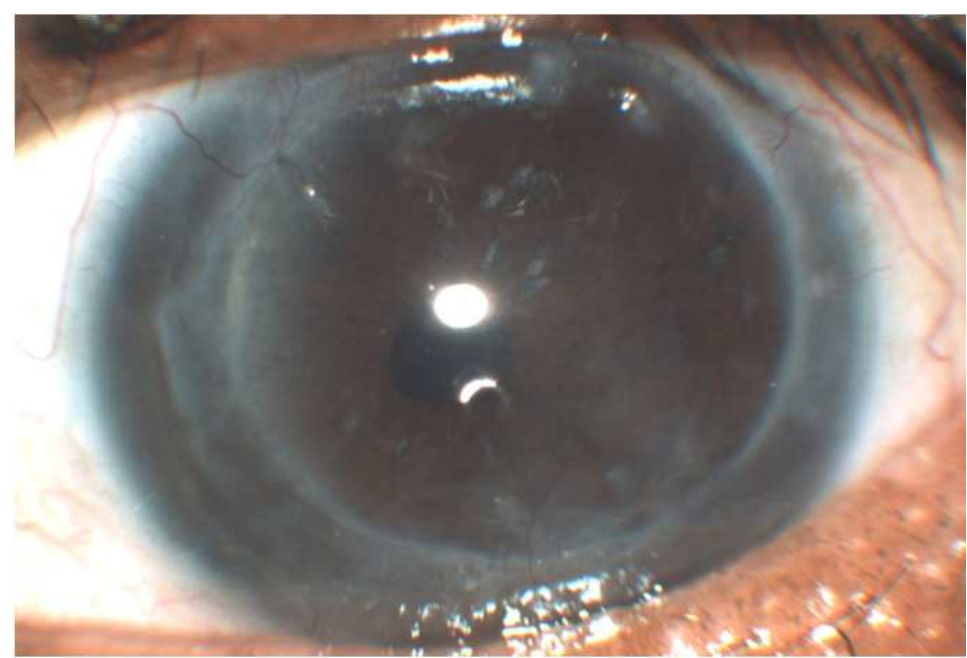

B

Fig. 2. Effect of topical bevacizumab on corneal neovasculariszation in a post-keratoplasty patient. A. Pre-treatment: Severe corneal vascularization and stromal haze is present. B. Post-treatment: Marked regression of corneal vascularization and reduction of stromal haze is observed 
with further regression in corneal vascularization and stromal haze resulted. At 9-month follow-up, he maintained BCVA of 20/60. Thus they concluded that short-term topical bevacizumab therapy may potentially offer a safer and more effective alternative in treating graft rejection after penetrating keratoplasty (Fig. 2).

Despite effective results, corneal thinning and epithelial defect following topical bevacizumab instillation has also been reported. ${ }^{13}$

\section{Conclusion}

Although limited number of studies are available in literature, growing evidence suggests that bevacizumab offers a safe and effective mode of treatment for graft rejection following penetrating keratoplasty.

\section{References}

[1] Maguire MG, Stark WJ, Gottsch JD, et al. Risk factors for corneal graft failure and rejection in collaborative corneal transplantation studies: Collaborative Corneal Transplantation Studies Research Group. Ophthalmology. 1994; 101: 1536-1547.

[2] Philipp W, Speicher L, Humpel C. Expression of vascular endothelial growth factor and its receptors in inflamed and vascularised human corneas. Invest Ophthalmol Vis Sci. 2000;41: 2514-2522.

[3] Cursiefen C, Masli S, Fong T, et al. Roles of thrombospondin- 1 and -2 in regulating corneal and iris angiogenesis. Invest Ophthalmol Vis Sci. 2004; 45: 1117-1124.

[4] Bachmann BO, Bock F, Wiegand SJ, et al. Promotion of graft survival by vascular endothelial growth factor-A neutralization after high-risk corneal transplantation. Arch Ophthalmol. 2008; 126: 71-77.

[5] Erdurmus M, Totan Y. Subconjunctival bevacizumab for corneal neovascularisation. Graefes Arch Clin Exp Ophthalmol 2007; 245: 1577-1579.

[6] Manzano RPA, Peyman GA, Khan P, Petros E, Kivilcim CM, Ren M, et al. Br J Ophthalmol. 2007;91:804-807.

[7] Dastjerdi MH, Al-Arfaj KM, Nallasamy N, Hamrah P, Jurkunas UV, Pineda R 2nd, et al. Arch Ophthalmol. 2009;127:381-389.

[8] Wei-Li Chen W , Chung-Tien Lin, Nien-Ting Lin, et al. Bevacizumab on corneal neovascularisation in different rabbit models of corneal angiogenesis. Invest Ophthalmol Vis Sci 2010 51:6277-6285.

[9] Carrasco MA. Subconjunctival bevacizumab for corneal neovascularization in herpetic stromal keratitis Cornea. 2008;27: 743-745.

[10] Bock F, König Y, Kruse F, Baier M, Cursiefen C. Bevacizumab eyedrops inhibit corneal neovascularization. Graefe's Arch Clin Exp Ophthalmol. 2008; 246: 281284.

[11] Schollmayer P, Stunf S, Lavric A. Pfeifer V. Topical and subconjunctival bevacizumab in corneal neovascularization in keratoplasty patients. Acta Ophthalmologica, 2008;86: 0. doi: 10.1111/j.1755-3768.2008.570.x 
[12] Saxena S, Kishore P, Pandey S, Khattri M, Kumar D. Topical bevacizumab for corneal neovascularization after penetrating keratoplasty.Eur J Ophthalmol. 2009;19:870872.

[13] Kim SW, Ha BJ, Kim EK, Tchah H, Kim TI. The effect of topical bevacizumab on corneal neovascularisation. Ophthalmology. 2008;115:E33-8. 


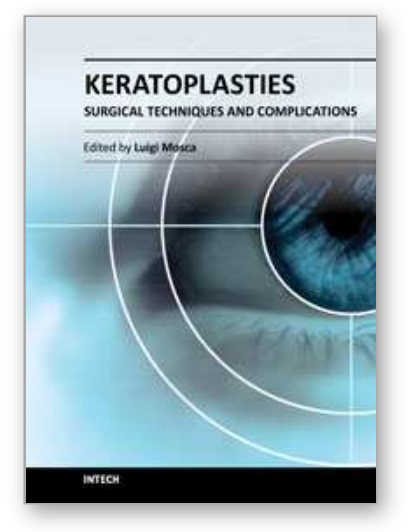

\author{
Keratoplasties - Surgical techniques and complications \\ Edited by Dr. Luigi Mosca
}

ISBN 978-953-307-809-0

Hard cover, 134 pages

Publisher InTech

Published online 18, January, 2012

Published in print edition January, 2012

In this book, the authors illustrate different therapeutic and surgical approaches to treating various corneal pathologies. This edition in electronic format allows universal access to everybody regardless of the time of day or setting, portability, and speed of information access. Such features show more feasibility for all readers and reduce the time necessary for research. This book will be a good tool for students as well as specialists working in the field of corneal transplantation, to improve their knowledge of treatment of corneal disease.

\title{
How to reference
}

In order to correctly reference this scholarly work, feel free to copy and paste the following:

Sandeep Saxena and Neha Sinha (2012). Topical Bevacizumab Therapy in Graft Rejection After Penetrating Keratoplasty, Keratoplasties - Surgical techniques and complications, Dr. Luigi Mosca (Ed.), ISBN: 978-953307-809-0, InTech, Available from: http://www.intechopen.com/books/keratoplasties-surgical-techniques-andcomplications/topical-bevacizumab-therapy-in-graft-rejection-after-penetrating-keratoplasty

\section{INTECH}

open science | open minds

\author{
InTech Europe \\ University Campus STeP Ri \\ Slavka Krautzeka 83/A \\ 51000 Rijeka, Croatia \\ Phone: +385 (51) 770447 \\ Fax: +385 (51) 686166 \\ www.intechopen.com
}

\author{
InTech China \\ Unit 405, Office Block, Hotel Equatorial Shanghai \\ No.65, Yan An Road (West), Shanghai, 200040, China \\ 中国上海市延安西路65号上海国际贵都大饭店办公楼 405 单元 \\ Phone: +86-21-62489820 \\ Fax: $+86-21-62489821$
}


(C) 2012 The Author(s). Licensee IntechOpen. This is an open access article distributed under the terms of the Creative Commons Attribution 3.0 License, which permits unrestricted use, distribution, and reproduction in any medium, provided the original work is properly cited. 